\title{
Safety and efficacy of denosumab in the treatment of pulmonary metastatic giant cell tumor of bone
}

This article was published in the following Dove Press journal: Cancer Management and Research

Yi Luo

Fan Tang

Yitian Wang

Yong Zhou

Li Min

Wenli Zhang

Rui Shi

Hong Duan

Chongqi Tu

Department of Orthopedics, West China Hospital, Sichuan University, Chengdu, China
Correspondence: Chongqi Tu

Department of Orthopedics, West China

Hospital, 37 Guoxue Xiang, Chengdu

61004I, Sichuan, China

Tel +86 I89 80601387

Fax +862885423438

Email tcqbonetumor@163.com
Background: Giant cell tumor (GCT) of bone is an intermittent and locally aggressive tumor with increasing pulmonary metastatic potential. In this study, we evaluated the interim clinical outcome of denosumab in patients with pulmonary metastatic GCT.

Materials and methods: We retrospectively reviewed seven patients with pulmonary metastatic GCT who received denosumab treatment after local tumor surgery during January 2014 and July 2016. Denosumab treatment for all patients lasted for at least 12 months. Serial chest computerized tomography scan was used to monitor the drug response and RECIST 1.1 standard was used to evaluate the therapeutic efficacy.

Results: All patients experienced chest pain relief in the first month of treatment. Three patients showed partial response. Four patients got stable disease after denosumab treatment. Adverse events included one patient with hypocalcemia and two patients with fever. No treatment-related deaths were reported. No patient with metastatic disease progression was found during an average of 28.6 months follow-up period.

Conclusion: We presented a promising interim clinical outcome using denosumab to treat patients with pulmonary metastatic GCT. Denosumab might be considered as the first-line treatment for patients with inoperable metastatic pulmonary GCT. However, Phase II clinical study with larger number of patients and longer follow-up period is needed to detect the further efficacy and safety of this drug for lung metastatic GCT.

Keywords: denosumab, giant cell tumor of bone, pulmonary metastasis, RANKL, recurrence

\section{Introduction}

Giant cell tumor (GCT) of bone is an intermittent tumor that is responsible for $\sim 6 \%$ of all primary bone tumors. Reported annual incidence of this tumor ranges between 1 and 6 per 10 million persons and shows a relatively high incidence in Chinese populations. ${ }^{1}$ It typically affects adults aged between 20 and 40 years, with a slightly higher incidence among females. ${ }^{2}$ The tumor is locally aggressive but with low metastatic potential despite maintaining a benign histology. ${ }^{3}$ The most common site of distant metastasis is lung, occurring at a frequency of $1 \%-9 \%$ in all GCT patients. ${ }^{4,5}$ Because of the unpredictable behavior, no standard treatment for GCT lung metastasis exists, and treatment options vary from metastasectomy, chemotherapy, radiation, or simple observation. ${ }^{6,7}$ The use of systemic antineoplastic chemotherapeutic agents has been confined to these few patients albeit with limited success. ${ }^{8}$ There are a lot of reports about bisphosphonates treatment for primary or recurrent GCT which have shown a variable but generally beneficial effect on tumor size. It may reduce the local recurrence 
rate after surgery. ${ }^{9}$ However, there are no exact reports about efficacy of bisphosphonate treatment for patients with pulmonary metastatic GCT. Surgery resection might be beneficial for patients with single metastatic lesion or other resectable pulmonary metastatic lesions. In order to avoid rapid increase of metastasis in volume and number, early detection and optimal follow-up observation periods are essential.

Treatment for GCT may considerably change with the advent of denosumab, which is a nuclear factor kappa-B ligand (RANKL) inhibitor. Giant cells in GCT have been confirmed to express RANKL, which causes the local aggressive nature of the tumor. In June 2013, FDA approved the application of denosumab in adults and skeletally mature adolescents with GCT deemed unresectable or requiring morbid surgery. ${ }^{10}$ But the efficacy of denosumab in pulmonary metastasis is currently unknown. Here, we followed up seven patients with pulmonary metastatic GCT treated in our hospital. These patients received aggressive curettage, bone cement filling, internal fixation for local tumor, and denosumab subcutaneously after surgery. Safety and efficacy of denosumab for these patients are evaluated.

\section{Materials and methods}

We retrospectively reviewed the charts of seven patients who underwent denosumab treatment during January 2014 and July 2016. The diagnoses of primary tumor of all patients were histologically confirmed. Specific tumor- and therapyrelated data were extracted from medical records, histologic sections, and radiographs for each patient after obtaining institutional review board approval for the study (Table 1).

Lung metastasis of GCT was diagnosed when histological examination of the metastatic lesions was confirmed or when radiological images met the following criteria: 1) development of abnormal lesions as single or multiple pulmonary nodules on chest radiography or nodular, rounded, well-defined opacities on chest computerized tomography (CT), and 2) growth either in number or size of the lesions during follow-up. ${ }^{11}$
Primary tumor locations are three at proximal tibias, two at distal femurs, one at pelvic, and one at distal radius. Local tumor of all seven patients was managed with aggressive curettage and bone graft, or following internal fixation with plate and screws, if it was necessary. Five patients were found to have lung metastasis disease within 2 years after local tumor surgery. Two patients were with pulmonary metastases at the initial diagnosis. Five patients received bisphosphonates treatment prior to denosumab.

Chest CT scan was used to assess lung metastasis lesions in all seven patients. Two patients received thoracoscopic surgery so that metastases of pulmonary lesions were histologically confirmed. After screening for contraindications and informed consent acquisition, patients were treated with denosumab with a dosage of $120 \mathrm{mg}$ subcutaneously on days $1,8,15,28$, and every 4 weeks thereafter. All patients took daily supplements of calcium ( $\geq 500 \mathrm{mg})$ and vitamin $\mathrm{D}(\geq 400$ IU). Responses and toxicity of this drug were assessed every 3 months based on physical examination, patients' reporting symptoms, and radiological imaging assessments. Adverse events were recorded and graded according to the National Cancer Institute Common Terminology Criteria for Adverse Events version 3.0.

Therapeutic efficacy of all patients was evaluated according to their chest CT scans every 3 months. New Response Evaluation Criteria in Solid Tumors (RECIST 1.1) was used to evaluate the therapeutic efficacy. The revised RECIST guideline (version 1.1) was published by the RECIST Working Group in January 2009, based in part on the investigations using the database consisting of $>6,500$ patients with $>18,000$ target lesions. $^{12}$

\section{Ethics approval and informed consent}

This study was approved by the Medical Ethics Committee of the West China Hospital. Written informed consent with regard to publication of this article and accompanying images was obtained from all the patients.

Table I Summary of the clinical features of the series

\begin{tabular}{|c|c|c|c|c|c|c|c|}
\hline Patient & Sex & $\begin{array}{l}\text { Age } \\
\text { (years) }\end{array}$ & Primary tumor site & Recurrence & $\begin{array}{l}\text { Follow-up } \\
\text { (months) }\end{array}$ & RECIST & Complications \\
\hline $\mathrm{I}$ & $\mathrm{F}$ & 32 & Proximal tibia & No & 20 & SD & Pain in extremities \\
\hline 2 & M & 44 & Pelvic & No & 19 & PR & Fever \\
\hline 3 & $\mathrm{~F}$ & 29 & Distal radius & No & 36 & PR & No \\
\hline 4 & $\mathrm{~F}$ & 26 & Proximal tibia & No & 22 & PR & No \\
\hline 5 & $M$ & 41 & Proximal tibia & No & 30 & SD & No \\
\hline 6 & M & 38 & Distal femur & No & 18 & $S D$ & Fever \\
\hline 7 & $M$ & 23 & Distal femur & No & 15 & $S D$ & No \\
\hline
\end{tabular}

Abbreviations: F, female; M, male; PR, partial response; RECIST, response evaluation criteria in solid tumors; SD, stable disease. 


\section{Results}

There were four male patients and three female patients, with an average age of 33.3 years ranging from 23 to 44 years. The average follow-up period was 22.9 months (ranging from 15 to 36 months; Table 1).

During the first month of treatment, all patients reported significant decrease in chest pain. Four patients reported free of chest pain after 6 months of treatment. The other three patients had significant reduction in chest pain after 6 months. All patients continually responded to treatment radiologically in 3 months. After 1 year, chest CT scans of three patients showed reduction in size and number of lung metastases, indicating partial response according to RECIST1.1. The other four patients got a stable disease and showed no disease progression. During the treatment, three patients $(42.9 \%)$ reported grade I or II adverse events (fever, pain). No severe adverse events were reported. Up to now, all the seven patients are still under denosumab therapy.

\section{Case report}

The third patient with distal radius GCT in Table 1 was a 29-year-old female. In March 2010, she received curettage, bone graft, and internal fixation with plate and screws for local tumor. Lung metastases were found through chest CT scans 2 years after surgery. Then, she was given bisphosphonates every month for 1 year. This patient started to use denosumab treatment in February 2014, as she experienced disease progression after the bisphosphonates treatment. The dosage of denosumab for this patient was $120 \mathrm{mg}$ subcutaneously on days $1,8,15,28$, and every 4 weeks thereafter (Figure 1).

The multi-lung metastatic nodules reduced in size after denosumab treatment. In August 2014, CT scans of this patient indicated a partial response according to RECIST 1.1 (Figure 2). In March 2015, there was no new measurable nodule and a total of three lesions disappeared on chest CT scans (Figure 3). In July 2016, that is, over 2 years after denosumab treatment, CT scans showed no new measurable
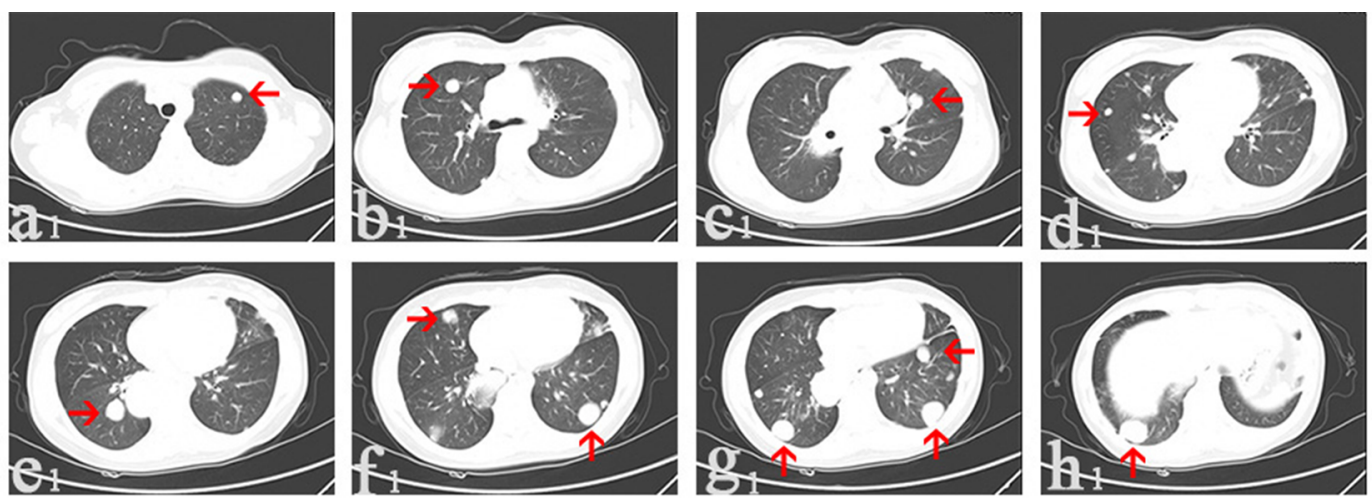

Figure I In February 2014, CT scans of the third patient before denosumab treatment showed multi-lung metastatic nodules (arrows).

Notes: The nodule was located on the left lung and grew to $\mathrm{I} \mathrm{cm}$ in diameter (al); the nodule was $1.2 \mathrm{~cm}$ in diameter (bl); the nodule was I.2 cm in diameter (cl); the nodule was $0.6 \mathrm{~cm}$ in diameter $(\mathrm{dl})$; the nodule was $2.2 \mathrm{~cm}$ in diameter $(\mathrm{el})$; the nodules were $\mathrm{I} .2$ and $2.2 \mathrm{~cm}$ in diameter ( $\mathrm{fl}$ ); two nodules were $2.2 \mathrm{~cm}$ and the other one was $1.2 \mathrm{~cm}$ in diameter $(\mathrm{gl})$; the nodule was $2.4 \mathrm{~cm}$ in diameter $(\mathrm{hl})$.

Abbreviation: $\mathrm{CT}$, computerized tomography.
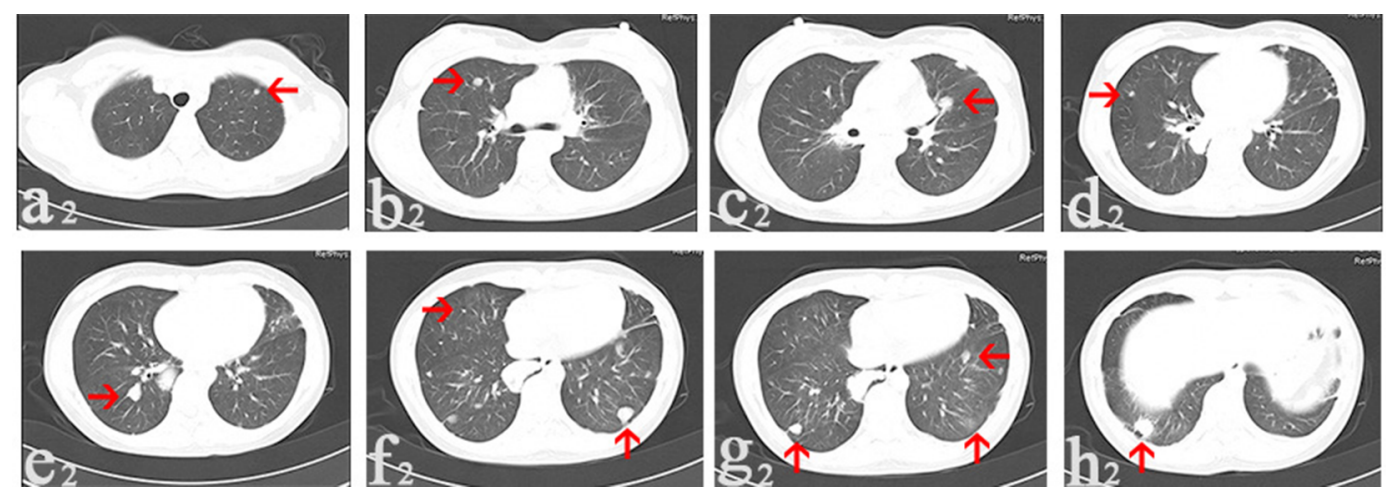

Figure 2 In August 2014, CT images collected after denosumab treatment for 6 months showed multi-lung metastatic nodules (arrows) reduced in size and number.

Notes: The nodule reduced to $0.4 \mathrm{~cm}$ in diameter (a2); the nodule reduced to $0.6 \mathrm{~cm}$ in diameter (b2); the nodule was with lower density than before and reduced to $1.0 \mathrm{~cm}$ in diameter (c2); the nodule reduced to $0.4 \mathrm{~cm}$ in diameter (d2); the nodule reduced to $1.2 \mathrm{~cm}$ in diameter (e2); the nodule on the right side reduced to $1.2 \mathrm{~cm}$ in diameter and the one on the left side disappeared (f2); one nodule disappeared and two nodules reduced to 1.0 and $0.8 \mathrm{~cm}$ in diameter ( $\mathrm{g} 2$ ); the nodule reduced to $1.4 \mathrm{~cm}$ in diameter ( $\mathrm{h} 2)$.

Abbreviation: CT, computerized tomography. 
nodules arisen. Compared to the CT scans in March 2015, the number and size of these nodules maintained stability (Figure 4). For this patient, there were no severe adverse events during denosumab treatment.

\section{Discussion}

GCT patients who are younger, presenting with Enneking grade 3 disease, developing local recurrence, or presenting with axial disease have an increased risk of pulmonary metastasis. The mean interval between primary diagnosis and the onset of lung metastases was 2.8 years in our study, which is similar to those of larger series with a mean interval of 2.0-4.1 years. ${ }^{7,13,14}$ The mode of treatment was not found to be associated with the development of pulmonary metastasis. ${ }^{6}$

The previous general consensus is that patients with persistent untreated pulmonary metastases of GCT of bone have a good long-term prognosis and excellent survival rate. ${ }^{13,15,16}$ However, as GCT have an increasing tendency of pulmonary metastasis in China, early detection of metastasis in GCT with regular long-term follow-up is recommend. ${ }^{4}$ Treatment for these patients with pulmonary disease is debatable. If possible, after the evaluation by thoracic surgeon, appropriate surgical resection including metastasectomy, wedge resection, or lobectomy might be performed to prevent progressive pulmonary dysfunction.

However, these metastatic pulmonary diseases are sometimes inoperative or surgery resection is aggressive and intolerable for patients. Besides, literature showed that pulmonary metastasectomy and chemotherapy might fail to produce a cure. ${ }^{17}$ In our study, five patients received bisphosphonates treatment prior to denosumab. Bisphosphonates have demonstrated therapeutic efficacy in osteolytic cancers and bone metastases, and combining with postoperative radiotherapy treatment might lead to a good local tumor control. ${ }^{18}$ It may be useful in controlling disease progression in GCT, and these agents directly inhibit GCT-derived osteoclast
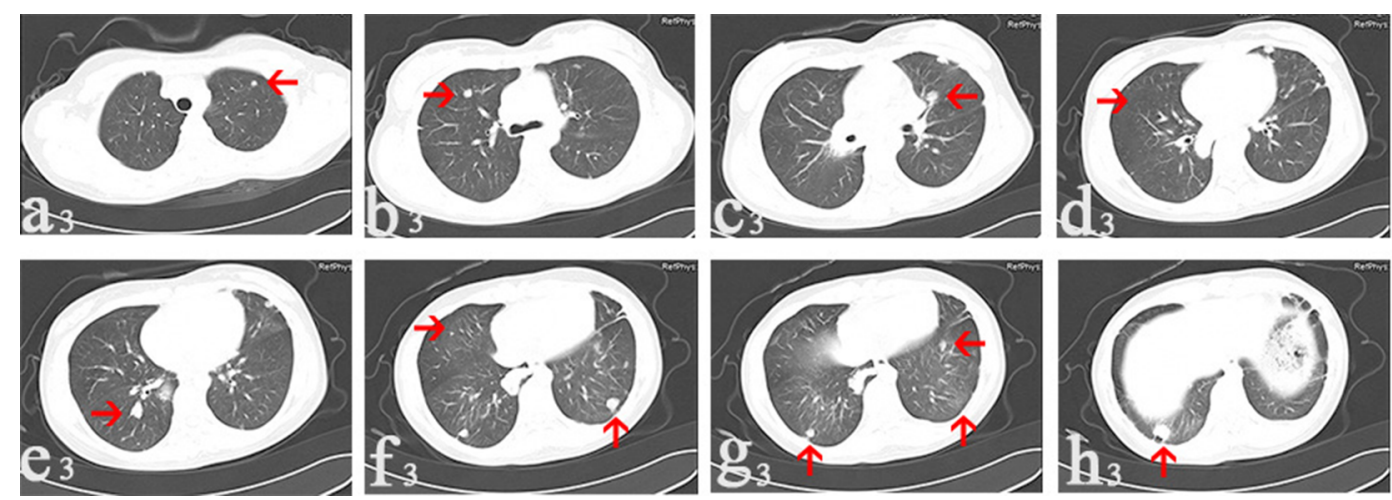

Figure 3 In March 20I5, CT images collected after denosumab treatment for 13 months

Notes: The nodule remained stable in size (a3); the nodule remained stable with size $0.6 \mathrm{~cm}$ in diameter (b3); the diameter of the nodule decreased to $0.8 \mathrm{~cm}$ (c3); one nodule disappeared on the right side $(\mathrm{d} 3)$; there was no change in the size of the nodule $(\mathrm{e} 3)$; the one on the left side reduced to $1.0 \mathrm{~cm}$ in diameter ( $\mathrm{f} 3$ ); the two nodules reduced to 0.8 and $0.6 \mathrm{~cm}$ in diameter, respectively $(\mathrm{g} 3)$; the nodule reduced to $1.2 \mathrm{~cm}$ in diameter (h3). Arrows point to the nodules.

Abbreviation: CT, computerized tomography.
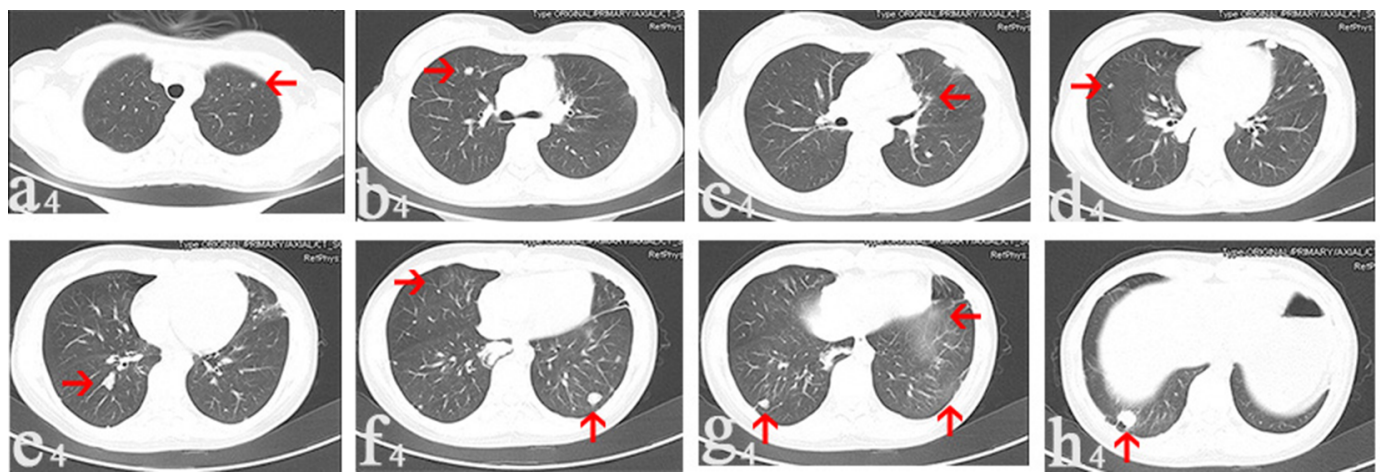

Figure 4 In July 2016, there was no new measurable nodule (arrows) on CT images collected after denosumab treatment for 29 months.

Notes: The nodule on the left side disappeared (g4). Number and size of these metastatic nodules maintain stability on all these eight images (a4, b4, c4, d4, e4, f4, h4), when compared with images in March 2015.

Abbreviation: CT, computerized tomography. 
resorption. ${ }^{19}$ Clinical use of bisphosphonates as adjuvants in treating patients with extremity GCT reduced the local recurrence rates to $4.2 \%$ (9\% in stage III GCT). ${ }^{20}$ The drug with proper dose can promote apoptosis of the stromal cell component in GCT and can reduce RANK-ligand expression in GCT stromal cell. ${ }^{21}$

Denosumab works by binding to RANKL and thus blocking binding to RANK on osteoclasts and osteoclast precursors, therefore inhibiting differentiation of osteoclasts and osteoclast-mediated bone reabsorption. It has been used to treat osteoporosis, bone metastases from solid tumors, and hypercalcemia of malignancy. As the giant cells in GCT also express RANK, denosumab is an attractive target-specific therapy for this tumor. ${ }^{22,23}$ It is already an effective and useful drug for managing GCT, especially when morbid surgery will be used to get good local tumor control. In addition, the drug has been used successfully for control of metastatic lung disease and may make resection of previously unresectable metastases possible according to a single case report. ${ }^{24}$ It might be considered as the gold standard for first-line treatment of patients with inoperable or metastatic GCT and can be used to downstage those with metastatic disease requiring aggressive surgery resection, but the timing of the use of neoadjuvant therapy in pulmonary tumors is debatable. ${ }^{25}$ Our study demonstrates a sustained clinical benefit, including chest pain reduction and radiological disease control, similar to a previous study. ${ }^{26}$ Approximately $42.9 \%$ of patients got partial response according to RECIST 1.1 , and the remaining $57.1 \%$ patients belonged to stable disease in this study.

Common adverse events after denosumab treatment include fatigue, nausea, dyspnea, and hypocalcemia. ${ }^{27}$ In our study, denosumab was associated with a decrease in skeletalrelated events, possibly reflecting superior inhibition of osteoclasts compared with zoledronic acid because of a different mechanism of action. Tsukamoto et al reported development of high-grade osteosarcoma in a patient with recurrent GCT of the ischium while receiving treatment with denosumab. This finding suggests that the scientific community should be aware of the possible malignant transformation of giant cell tumor of bone during denosumab treatment. ${ }^{28}$ George reported a case of rapid recurrent following cessation of denosumab therapy. Thus, he concluded that patients need to maintain regular life-long denosumab therapy or definitive surgical treatment should be performed prior to cessation of therapy. ${ }^{29}$ So, there is a major concern that denosumab withdrawal is associated with a high rate of subsequent progression. ${ }^{29,30}$
Overall, our study presents a promising interim clinical outcome using denosumab in patients with pulmonary metastatic GCT. Denosumab treatment might produce a surgery chance for those who are with unresectable pulmonary metastatic disease. However, there is still much to do in considering its clinical use for different stages of GCT. The optimal treatment schedule in long-term maintenance therapy with less frequent dosage is not known and should be the subject of ongoing research. Full dataset of large Phase II study is essential to confirm the safety for long-term use. Due to the challenges of treating this metastatic disease and the unanswered questions regarding optimal use of denosumab, referral and follow-up of complicated cases of GCT requiring denosumab should be within expert bone cancer centers.

\section{Acknowledgment}

We wish to acknowledge funding in support of Yi Luo by the Support Program for Science and Technology of Sichuan Province, China (2017SZ0106).

\section{Disclosure}

The authors report no conflicts of interest in this work.

\section{References}

1. Beebe-Dimmer JL, Cetin K, Fryzek JP, Schuetze SM, Schwartz K. The epidemiology of malignant giant cell tumors of bone: an analysis of data from the Surveillance, Epidemiology and End Results Program (1975-2004). Rare Tumors. 2009;1(2):e52.

2. Mendenhall WM, Zlotecki RA, Scarborough MT, Gibbs CP, Mendenhall NP. Giant cell tumor of bone. Am J Clin Oncol. 2006;29(1):96-99.

3. Tandra VS, Kotha KM, Satyanarayana MG, Vadlamani KV, Yerravalli V. Synchronous multicentric giant cell tumour of distal radius and sacrum with pulmonary metastases. Case Rep Oncol Med. 2015;2015:354158.

4. Niu X, Zhang Q, Hao L, et al. Giant cell tumor of the extremity: retrospective analysis of 621 Chinese patients from one institution. $J$ Bone Joint Surg Am. 2012;94(5):461-467.

5. Bertoni F, Present D, Sudanese A, Baldini N, Bacchini P, Campanacci M. Giant-cell tumor of bone with pulmonary metastases. Six case reports and a review of the literature. Clin Orthop Relat Res. 1988;237:275-285.

6. Chan CM, Adler Z, Reith JD, Gibbs CP Jr. Risk factors for pulmonary metastases from giant cell tumor of bone. J Bone Joint Surg Am. 2015;97(5):420-428.

7. Dominkus M, Ruggieri P, Bertoni F, et al. Histologically verified lung metastases in benign giant cell tumours-14 cases from a single institution. Int Orthop. 2006;30(6):499-504.

8. Osaka S, Toriyama M, Taira K, Sano S, Saotome K. Analysis of giant cell tumor of bone with pulmonary metastases. Clin Orthop Relat Res. 1997(335):253-261.

9. Arpornchayanon O, Leerapun T. Effectiveness of intravenous bisphosphonate in treatment of giant cell tumor: a case report and review of the literature. J Med Assoc Thai. 2008;91(10):1609-1612.

10. Goldenberg MM. Pharmaceutical approval update. PT. 2013;38(8): 443-445.

11. Rosario M, Kim HS, Yun JY, Han I. Surveillance for lung metastasis from giant cell tumor of bone. J Surg Oncol. 2017;116(7):907-913.

12. Eisenhauer EA, Therasse P, Bogaerts J, et al. New response evaluation criteria in solid tumours: revised RECIST guideline (version 1.1). Eur J Cancer. 2009;45(2):228-247. 
13. Siebenrock KA, Unni KK, Rock MG. Giant-cell tumour of bone metastasising to the lungs. A long-term follow-up. J Bone Joint Surg Br. 1998;80(1):43-47.

14. Tubbs WS, Brown LR, Beabout JW, Rock MG, Unni KK. Benign giantcell tumor of bone with pulmonary metastases: clinical findings and radiologic appearance of metastases in 13 cases. AJR Am J Roentgenol. 1992;158(2):331-334.

15. Cheng JC, Johnston JO. Giant cell tumor of bone. Prognosis and treatment of pulmonary metastases. Clin Orthop Relat Res. 1997;338: 205-214.

16. Gupta R, Seethalakshmi V, Jambhekar NA, et al. Clinicopathologic profile of 470 giant cell tumors of bone from a cancer hospital in western India. Ann Diagn Pathol. 2008;12(4):239-248.

17. Jacopin S, Viehweger E, Glard Y, et al. Fatal lung metastasis secondary to index finger giant cell tumor in an 8-year-old child. Orthop Traumatol Surg Res. 2010;96(3):310-313.

18. Wolanczyk MJ, Fakhrian K, Adamietz IA. Radiotherapy, bisphosphonates and surgical stabilization of complete or impending pathologic fractures in patients with metastatic bone disease. J Cancer. 2016;7(1): 121-124.

19. Balke M, Campanacci L, Gebert C, et al. Bisphosphonate treatment of aggressive primary, recurrent and metastatic Giant Cell Tumour of Bone. BMC Cancer. 2010;10:462.

20. Tse LF, Wong KC, Kumta SM, Huang L, Chow TC, Griffith JF. Bisphosphonates reduce local recurrence in extremity giant cell tumor of bone: a case-control study. Bone. 2008;42(1):68-73.

21. Cheng YY, Huang L, Lee KM, Xu JK, Zheng MH, Kumta SM. Bisphosphonates induce apoptosis of stromal tumor cells in giant cell tumor of bone. Calcif Tissue Int. 2004;75(1):71-77.
22. Hanley DA, Adachi JD, Bell A, Brown V. Denosumab: mechanism of action and clinical outcomes. Int J Clin Pract. 2012;66(12):1139-1146.

23. Xu SF, Adams B, Yu XC, Xu M. Denosumab and giant cell tumour of bone-a review and future management considerations. Curr Oncol. 2013;20(5):e442-e447.

24. Karras NA, Polgreen LE, Ogilvie C, Manivel JC, Skubitz KM, Lipsitz E. Denosumab treatment of metastatic giant-cell tumor of bone in a 10-year-old girl. J Clin Oncol. 2013;31(12):e200-e202.

25. Gaston CL, Grimer RJ, Parry M, et al. Current status and unanswered questions on the use of Denosumab in giant cell tumor of bone. Clin Sarcoma Res. 2016;6(1):15.

26. Traub F, Singh J, Dickson BC, et al. Efficacy of denosumab in joint preservation for patients with giant cell tumour of the bone. Eur $J$ Cancer. 2016;59:1-12.

27. Lipton A, Stopeck A, Moos Rv, et al. A meta-analysis of results from two randomized, double-blind studies of denosumab versus zoledronic acid (ZA) for treatment of bone metastases. J Clin Oncol. 2010;28(15 Suppl):9015.

28. Tsukamoto S, Righi A, Vanel D, Honoki K, Donati DM, Errani C. Development of high-grade osteosarcoma in a patient with recurrent giant cell tumor of the ischium while receiving treatment with denosumab. Jpn J Clin Oncol. 2017;47(11):1090-1096.

29. Matcuk GR Jr, Patel DB, Schein AJ, White EA, Menendez LR. Giant cell tumor: rapid recurrence after cessation of long-term denosumab therapy. Skeletal Radiol. 2015;44(7):1027-1031.

30. Rosario M, Takeuchi A, Yamamoto N, et al. Pathogenesis of osteosclerotic change following treatment with an antibody against RANKL for giant cell tumour of the bone. Anticancer Res. 2017;37(2):749-754.
Cancer Management and Research

\section{Publish your work in this journal}

Cancer Management and Research is an international, peer-reviewed open access journal focusing on cancer research and the optimal use of preventative and integrated treatment interventions to achieve improved outcomes, enhanced survival and quality of life for the cancer patient. The manuscript management system is completely online and includes

\section{Dovepress}

a very quick and fair peer-review system, which is all easy to use. Visit http://www.dovepress.com/testimonials.php to read real quotes from published authors. 